\title{
BMJ Open Implementation of patient-centred care: which system-level determinants matter from a decision maker's perspective? Results from a qualitative interview study across various health and social care organisations
}

\author{
Carmen Leidner, ${ }^{1}$ Vera Vennedey (1) , ${ }^{2}$ Hendrik Hillen, ${ }^{3}$ Lena Ansmann, ${ }^{4}$ \\ Stephanie Stock, ${ }^{2}$ Ludwig Kuntz, ${ }^{3}$ Holger Pfaff, ${ }^{5}$ Kira Isabel Hower (D), , On behalf \\ of the CoRe-Net Co-applicants
}

To cite: Leidner C, Vennedey V, Hillen $\mathrm{H}$, et al. Implementation of patient-centred care: which system-level determinants matter from a decision maker's perspective? Results from a qualitative interview study across various health and social care organisations. BMJ Open 2021;11:e050054. doi:10.1136/ bmjopen-2021-050054

- Prepublication history and additional supplemental material for this paper are available online. To view these files, please visit the journal online (http://dx.doi.org/10.1136/ bmjopen-2021-050054).

Received 08 February 2021 Accepted 02 August 2021

A) Check for updates

(C) Author(s) (or their employer(s)) 2021. Re-use permitted under CC BY-NC. No commercial re-use. See rights and permissions. Published by BMJ.

For numbered affiliations see end of article.

Correspondence to

Kira Isabel Hower;

kira.hower@uk-koeln.de

\section{ABSTRACT}

Objectives The healthcare system is characterised by a high degree of complexity and involves various actors at different institutional levels and in different care contexts. To implement patient-centred care (PCC) successfully, a multidimensional consideration of influencing factors is required. Our qualitative study aims to identify system-level determinants of PCC implementation from the perspective of different health and social care organisations (HSCOs).

Design A qualitative study using $n=20$ semistructured face-to-face interviews with $n=24$ participants was carried out between August 2017 and May 2018. Interview data were analysed based on concepts of qualitative content analysis using an inductive and deductive approach.

Setting and participants Interviews were conducted with clinical and managerial decision makers from multiple HSCOs in the model region of Cologne, Germany. Participants were recruited via networks of practice partners and cold calling.

Results This study identified various determinants on the system level that are associated with PCC implementation. Decision makers described external regulations as generating an economically controlled alignment of the healthcare system. The availability and qualification of staff resources and patient-related incentives of financial resources were identified as an eminent requirement for providers to deliver PCC. Participants considered the strict separation of financing and delivery of healthcare into inpatient and outpatient sectors to be a barrier to PCC. Interorganisational collaboration and information exchange were identified as facilitators of PCC, as they enable continuous patient care cycles.

Conclusion The results showed the necessity of enforcing paradigm changes at the system level from diseasecentredness to patient-centredness while aligning policy and reimbursement decisions directly with patient needs and values. A systematic, long-term planned strategy that extends across all organisations is lacking, rather each
Strengths and limitations of this study

- As the participants of the study are decision makers from health and social care organisations (HSCOs) in various healthcare contexts, the identified determinants reflect the wide range of heterogeneous healthcare organisations from an internal practical perspective.

- The computer-assisted qualitative content analysis based on the Consolidated Framework for Implementation Research and a systematic literature review ensures a systematic and methodically controlled text analysis.

When generalising the results to different healthcare systems, specifics of the German healthcare system need to be taken into account, as only German HSCO decision makers were interviewed.

- As the participants received no compensation for participation, they might have had higher motivation and interest in the research topic and might be more likely to put effort into patient-centred care activities if incentives were offered.

organisation seeks its own possibilities to implement PCC activities under external restrictions.

Trial registration number

DRKS00011925

\section{INTRODUCTION}

As awareness of its merits is growing, patientcentred care (PCC) has received increasing attention as a fundamental concept in healthcare provision, along with its aspiration to focus on patients' needs and preferences, and to involve the patient in the provision of healthcare. $^{1-3}$ This marks a departure from 
previously dominant biomedical, disease-centred healthcare provision. ${ }^{45}$

Although the literature has dealt with PCC for several years, a clear and common understanding in research is missing. ${ }^{2}$ A widely used definition used by the Institute of Medicine describes PCC as "providing care that is respectful of, and responsive to, individual patient preferences, needs and values, and ensuring that patient values guide all clinical decisions' ${ }^{6}$ The implementation of PCC structures has been shown to improve healthcare provision in the face of increasing demand for health services and limited resources by affecting economic aspects (eg, reduced resource utilisation, improved costeffectiveness), as well as patient-related features (eg, better health outcomes, higher patient satisfaction). ${ }^{7-10}$

PCC is characterised by its multidimensionality, which has been described with various models and frameworks. These models vary by healthcare setting and level of activity, but they share interconnecting dimensions of the PCC concept as individualised care for patients, patient information and involvement in care, physical and emotional support, integration of medical and nonmedical care, access to care and coordination and continuity of care. ${ }^{11}$

Successful implementation requires a practical analysis of determinants, their relation to each other and their extent of influence. ${ }^{211}$ Therefore, the research project OrgValue explores the decision makers' as well as the patients' perspective on the implementation of PCC in the metropolitan region of Cologne, Germany. ${ }^{12}$ Within this study, determinants of PCC implementation at the organisational and individual levels across different health and social care organisations (HSCOs) have already been explored. ${ }^{13}$ Determinants on the level of the healthcare system have still to be examined.

The healthcare system shows a high degree of complexity and involves various actors at different institutional levels and in different care contexts in the regulation and provision of healthcare. In the German healthcare system, the strong division into inpatient and outpatient healthcare sectors poses a particular challenge. Consequently, the conditions, interests and availability of resources vary between different HSCOs. ${ }^{14}{ }^{15}$ A multiperspective approach is required taking into account the viewpoints of different healthcare actors. ${ }^{1116}$

Prior research agrees that determinants influencing the implementation of PCC occur at the system level, as well as at the individual and organisational levels. The definition of system level in this paper is based on the defined outer setting dimension of the Consolidated Framework for Implementation Research (CFIR) ${ }^{17}$ and includes the wider social, cultural, political and economic context. ${ }^{81819}$

Identified system-level determinants of the implementation of PCC activities identified in the literature so far include regulatory policies, ${ }^{11}{ }^{20-22}$ funding, ${ }^{22-24}$ qualification of healthcare professionals ${ }^{825}$ and healthcare system characteristics and structures. ${ }^{18}$ 22-24 Online supplemental appendix table 1 gives an overview of implementation determinants-general system-level determinants of healthcare interventions as well as determinants specific to the implementation of PCC. However, previous research does not provide an overview of facilitating and hindering influences of PCC implementation at the system level can be applied across care settings and consider different perspectives of decision makers in the healthcare system.

Accordingly, this study aims to advance research on determinants of PCC implementation and complements our previous analysis of organisational and individual determinants ${ }^{13}$ by identifying PCC-related determinants on the system level as perceived from HSCO perspectives in various care contexts. Designed as a qualitative interview study, the research was conducted to provide an overview of determinants faced by HSCOs on the system level, assessing common determinants across different healthcare contexts.

\section{METHODS}

\section{Setting: German health and social care system}

Within the framework of the social health insurance set by the German state, regulation, organisation and distribution of financial resources of healthcare services are delegated to institutions of the joint self-government. The highest decision-making body is the Federal Joint Committee (in German: Gemeinsamer Bundesausschuss (G-BA)), in which providers, payers and patients are represented. G-BA regulations are legally binding on all healthcare actors. As the healthcare system strictly differentiates between inpatient and outpatient actors, healthcare delivery and financing also generally observe this division. Ambulatory care is mostly provided by general practitioners (GP), specialists and ambulatory healthcare centres. Inpatient care is provided by hospitals, rehabilitation institutes and long-term care. Each of the healthcare fields is subject to a different mode of financing. The extensive separation of care sectors is seen as a challenge to the German healthcare system because it complicates the provision of continuous care and information transfer processes. $^{26}$

In Germany, the principle of 'free choice of physicians' exists, under which insured persons can decide for themselves which physician, dentist or psychotherapist they wish to consult. GPs are assigned responsibilities for coordinating care-for example, writing referrals to specialists-but they have no defined gatekeeper function. The provision of outpatient services via hospitals has not been standard practice up to now and is only possible via selective contracts between single providers and social health insurance companies in the course of special and integrated care (in German: besondere und integrierte Versorgung) ${ }^{26} 27$ The implementation of PCC activities in the German regulatory setting of the healthcare system is currently bolstered by the implementation of disease management programmes, ${ }^{28}$ adjustments to the Law on Patient Rights and research programmes in this field. ${ }^{29-31}$ 


\section{Study design}

The present qualitative study is part of the research project OrgValue (Characteristics of Value-Based Health and Social Care from Organizations' Perspectives) which is embedded in the Cologne Care Research and Development Network (CoRe-Net). CoRe-Net is an interdisciplinary cooperative effort that enables the integration of different perspectives and methods in the investigation of cross-sectoral healthcare for specific patient groups in Cologne, Germany. Presently, it carries out four subprojects. ${ }^{32}$ The subproject OrgValue aims to examine the implementation of patient-centredness in the metropolitan region of Cologne from organisations and patients' perspectives. ${ }^{12}$ The mixed methods study combines qualitative and quantitative social research. This analysis is based on qualitative interviews with HSCO decision makers. ${ }^{13}$

\section{Sampling and data collection}

The interviewees reflect a sample of HSCOs involved in caring for vulnerable patient groups studied in the accompanying projects within CoRe-Net in the metropolitan region of the city of Cologne, Germany. Clinical and managerial decision makers with different (in some cases multiple) functionalities were interviewed to obtain multiple perspectives. Online supplemental appendix table 2 provides an overview of participant characteristics, such as gender, type of care organisation and organisational tenure. Researchers of the OrgValue project conducted the interviews face to face. A semistructured qualitative interview guide was developed focusing on three main topics:

- How do decision makers define PCC?

- What obstructs or facilitates the implementation of PCC in their organisation?

- How do organisations deal with their resources, that is, which resources are needed or lacking for implementation?

Core questions and narrative-generating subquestions operationalised each topic. Interviews were audiotaped and transcribed verbatim and anonymised by an external professional typist. Further information on sampling, data collection and interviewee characteristics can be found elsewhere. ${ }^{13}$

\section{Patient and public involvement}

Patients and members of the public were not involved in the conduct of this study. However, this study is embedded within CoRe-Net, which is a network of scientists, patient organisations, HSCOs, municipality representatives and other stakeholders. ${ }^{32}$ CoRe-Net members participated in developing ideas for the OrgValue project, its conduction and data collection. ${ }^{12}$

\section{Data analysis}

Interviews were audiotaped, transcribed verbatim and anonymised by an external professional typist. All transcripts were entered into the computer-assisted qualitative data analysis software 'MAXQDA', which was used to code and manage data (VERBI, Berlin, Germany).

The semistructured interviews were analysed using qualitative content analysis (QCA). QCA fits the intention of this study which is to extract data content in a descriptive, systematic and conceptualising way that reflects the perspectives of the interviewees from different HSCOs but does not identify underlying meanings. ${ }^{33}$

A coding frame consisting of system-level determinants was developed in a multistage process of deductive and inductive coding. Figure 1 displays the entire coding process step by step. As a first step, transcripts were read and important text passages marked, which allowed for familiarisation with the contents of the interviews. In advance of the first coding cycle, a concept-driven, deductive strategy was used to create an initial coding frame based on established theories and previous research experience. ${ }^{33}$ Dimensions of the CFIR provided the foundation for the deductive framework. The CFIR is a wellestablished meta-theoretical framework that provides an assortment of implementation-related constructs organised across five major domains, all of which interact to influence implementation: intervention characteristics, outer setting, inner setting, characteristics of the individuals involved and process of implementation. We used the category 'outer setting' of the CFIR to capture and categorise the determinants of PCC implementation which includes the categories of patient needs and resources, cosmopolitanism, peer pressure, external policies and incentives. ${ }^{17}$ To strengthen the coding foundation, the deductive framework was further developed alongside the CFIR categories by other constructs derived from the pertinent research literature on system-level determinants (online supplemental appendix table 1). Reliability was strengthened by defining all categories before analysis and storing them in the software to prevent misunderstandings or inconsistent assignment of units of analysis to codes. ${ }^{33}$

The initial coding framework was used to code the entire material in the first-cycle coding. After the first coding process using the established deductive framework, the existing codes were further differentiated and subcodes formed according to inductive category formation. ${ }^{33}$ The deductive coded text areas were worked through, summarised if necessary and new subcodes extracted from them. After each redefinition of codes and subcodes, the previously coded material was reviewed again and recoded, if necessary. The final coding agenda can be found in the online supplemental appendix.

\section{RESULTS}

For the data analysis, 20 interviews with 24 decision makers on 20 different dates were used. The 24 interviewed decision makers were divided into private practice GPs and specialists $(n=3)$, psychotherapists $(n=3)$, longterm outpatient care $(n=4)$, outpatient rehabilitation 


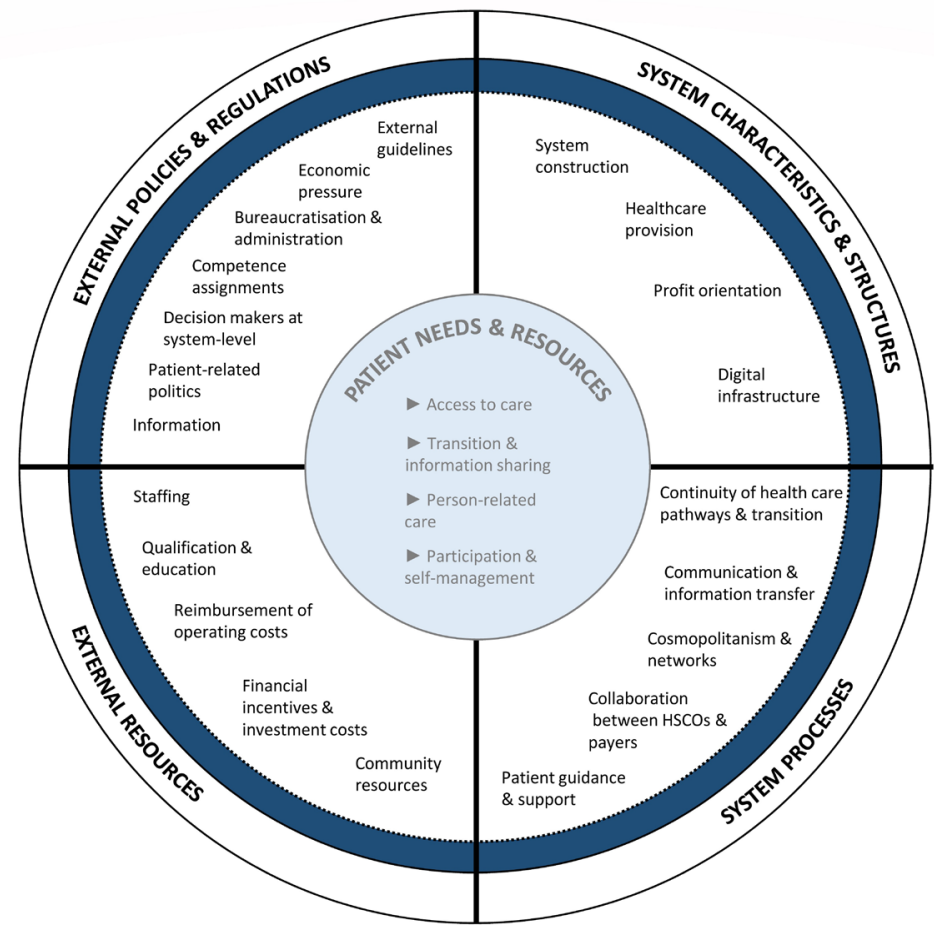

Figure 1 System-level determinants of patient-centred care (PCC) implementation. HSCO, health and social care organisation.

services and rehabilitation clinics $(n=4)$, long-term inpatient care $(n=5)$ and hospitals $(n=5)$.

Online supplemental appendix table 3 provides an overview of the developed categories, including a short description of each code. Determinants of PCC implementation related to external policies and regulation, system characteristics and structures, system processes and external resources are described, substantiated by quotes from the interviews (table 1). Along with the coding framework, results are presented as textual fragments summarising the content of the coded interview segments. Relevant passages were translated into English.

The category 'patient needs and resources' was identified as a central element of the determinant framework, as the extent to which patient needs and resources are recognised and prioritised at the system level defines the extent to which PCC activities can be implemented in HSCOs. Descriptions and quotations for codes in this category can be found in the online supplemental appendix tables 4 and 5 .

\section{System characteristics and structures \\ System construction}

Some decision makers described the overall healthcare system as complex and conservative with many interacting stakeholders impeding the implementation of new concepts. In addition, the basic structure of the system with its division from the top level down in inpatient and outpatient care was assessed as obstructive, which is related to the content of the category system processes, as explained below.

\section{Healthcare provision}

Several interviewees connected deficits in healthcare provision to capacity deficits in various sectors. They described deficits as internal systemic obstacles to guaranteeing the best possible-(ie, timely and comprehensive)-patient care. Deficits in long-term care (ie, insufficient nursing home vacancies or lack of available outpatient services) were described as hampering the continuity of care after patients are discharged from the hospital.

\section{Profit orientation}

The focus on continuous growth and profit maximisation in healthcare has been seen as threatening a shift away from prioritising patient welfare and towards economic considerations. Although all providers acknowledged the need to economise, they associated a focus on patient well-being with a certain set of values as being incompatible with strictly economic thinking and, therefore, more commonly linked to non-profit than for-profit organisations. In this context, interviewees questioned the paradigm of economic growth in the sense that current healthcare provision is most often a matter of providing the most innovative medicine and more services to increase profit without considering the extent to which these improvements serve the well-being and needs of patients.

\section{Digital infrastructure}

Interviewees described deficits of digitalisation in the healthcare sector as disrupting care structures and patient orientation. They emphasised that integrative, person-centred and timely provision of health-related patient information and efficient exchange of such information among service 
Table 1 Determinants of PCC implementation related to the system level

\section{Determinant Quotes}

\section{System characteristics and structures}

System construction 'So, I already feel that the health care sector or the hospital sector is a very conservative area, so the willingness to do things in new ways is not very pronounced. [...] because with actors all enmeshed like gears, it is of course extremely difficult to turn any adjusting screw without completely disrupting the overall system.

'Well, I think this sector separation needs to be softened. This fragmentation of conditions and responsibilities does not benefit the patient.'

Healthcare provision ' $[\ldots]$ and then you hear we're already the eighth caregiver l've called. Well, in the meantime, nursing care is so understaffed in many regions that ad hoc care is not possible in many cases, and that as a nurse you really have to choose who I want and who can care for.'

Profit orientation 'And otherwise I do believe that this profit-driven health care system is not reasonable. That health is not a commodity. I think so. And that everything should not always be geared towards optimizing the financial situation.'

'That means in terms of practice it is an individual decision how to digitize, how to equip my clinic, how far am I willing to make investments to make a clinic work quickly and efficiently.'

Digital infrastructure 'But also the topic of digitalization. I think that here in the hospital we are still at the back end of the queue with digitalization, as far as the care processes are concerned. The systems don't talk to each other, the interfaces are not properly linked. [...] I think that the topic of standardizing interfaces and information systems should be given from the very top."

'That means in terms of practice it is an individual decision how to digitize, how to equip my clinic, how far am I willing to make investments to make a clinic work quickly and efficiently.'

\section{System processes}

Continuity of care processes and transition

Communication and information sharing

Cosmopolitanism

and networks

\section{'What is often a problem for patients is the time after discharge. And, of course, as a hospital, this can only be achieved to a} certain extent, because in the end, the remuneration ends when the threshold is crossed.'

'And of course, in some situations or cases, it is difficult to ensure a flow. That is, regardless of whether it is a rehab place or a home for the elderly or home outpatient care or similar, so this downstream care is not quite so simple, even in Cologne.'

'For me, not only the communication within my own professional group is a decisive factor, but also how one professional group communicates with others [...] And I also believe that these parameters [...] are needed for certain interventions in order to be able to work person-centred. [...] There are breaks, [...] This may be because information does not flow, or the communication of information is not continuous [...].' 'If I take the field of oncology now [...] both inpatient and outpatient, we have the possibility to provide care in the form of an oncology unit, a palliative care unit, a hospice [...] and in the other direction, we have access to outpatient practices. [...] Another example is that we have cooperation with owners in the same practice [...] with whom we have a very trustful relationship where the physicians work half in the hospital and half in the practice, it works well there. They admit the patients, they take care of them as in-patients, and then they go back to the general practitioners.

Collaboration 'Yes, often, for example, when it comes to the supply of medical aids, to (clicks) when a resident needs a specially adapted new between HSCOs and wheelchair, then it often takes weeks [...] until the right aid is available on site. And I experience this as very, very long. So this ... payers sometimes the aid that we would actually need is no longer needed by the time it actually arrives.

'In the last nine months, I have in fact come so far from accepting cost reimbursement patients because the social health insurances, I have to say it so clearly, have become really impudent.'

Patient guidance and ' $[. .$.$] you can almost study that at the university level, right? How do I get a therapy place? And what is the difference between$ support a psychiatrist, psychological psychotherapist, medical psychotherapist, counselling. [...] then there are the different therapeutic directions, [...] Well, I don't find it easy to find my way around that at all if I'm also someone [...] who's not well. And who actually just wants help.

'[t]hat you're a little more patient-oriented, that you really look at what he [the patient] needs when he needs it and how he gets there. Yes? And what assistance exists, what support options are there, and what is a person entitled to in such a situation?'

\section{External resources}

\begin{tabular}{|c|c|}
\hline Staffing & $\begin{array}{l}\text { '[...] the subject of skilled workers is of course ... or shortage of skilled workers, the main topic in the branch, which also has an } \\
\text { effect on patient orientation, from my point of view.' } \\
\text { 'These are really structural problems and you can't really fight them. And of course, we are also noticing that the ratio of skilled } \\
\text { workers on the market is decreasing. [...] Although we have good opportunities here or really offer great pay for skilled workers } \\
\text { themselves compared to our competitors, there are not many left.' }\end{array}$ \\
\hline $\begin{array}{l}\text { Qualification and } \\
\text { education }\end{array}$ & $\begin{array}{l}\text { 'I think, the topic of skilled workers, we are really heading for this situation, where it becomes the bottleneck in the economy and } \\
\text { you have to fear that on the one hand, if you no longer have skilled workers, you will go into a D-qualification. In other words, } \\
\text { anyone can do anything. Following the principle, four week nursing staff who give injections, hang infusions and so on at the end. } \\
\text { '...because there's nobody else.' } \\
\text { 'And also the quality of the staff. Do I only work with assistants or do the people know what they have to do, right? And that's } \\
\text { becoming more and more of an issue these days.' }\end{array}$ \\
\hline $\begin{array}{l}\text { Reimbursement of } \\
\text { operating costs }\end{array}$ & $\begin{array}{l}\text { 'I think what's very important is that you have to be able to respond to changing needs, depending on a person's condition on a } \\
\text { given day, right? [...]. So, to get out of these organisational constraints and to have the freedom to decide every day anew, what } \\
\text { is it that the patient needs today? [...] That freedom is not there because outpatient care depends on these fixed fees for groups } \\
\text { of services and you can only bill for an entire complex.' } \\
\text { 'The time now to communicate again by telephone or other, personal things with external facilities, this is not given. This is just } \\
\text { stupidly not provided for in the system. So, there is no paid time for that. That's a pity, but that's how it is.' } \\
\text { 'The [budget regulation] is basically not wrong with trying to limit a budget ... or costs. Unnecessary costs. On the other hand, } \\
\text { such lump-sum budgets are of course sometimes unnecessarily restrictive from a systemic point of view, because they do not } \\
\text { take any special cases or few special cases into account.' }\end{array}$ \\
\hline
\end{tabular}


Table 1 Continued

Determinant Quotes

Financial incentives 'These are such rigid structures; it is not intended that innovations are brought in now. At least not if you want some form of and investment costs financing. [...] It's just something we buy to [...] offer the patient improved care. But nothing where we know that we'll get rich now, or even that we can recoup these costs soon.'

'Yes, it's about the financing. For example, this project [.] won't be financed. Professor [.] set this up as a pilot and said that we had to finance it out of our own pocket because we expect to benefit from it. For patient care and the quality of patient care. [...] there is again no regular funding for such projects and there has not been any funding from foundations to date. But I think that this is a promising approach for the future.'

$\begin{array}{ll}\text { Community } & \text { 'The fact that people say that we have active church communities [...] they should not only be working next to each other, but } \\ \text { resources } & \text { rather working hand in hand with each other, knowing about each other, supporting each other, including the volunteers in the } \\ & \text { work. And from this (name of the association) can still benefit greatly from the fact that volunteers can be involved.' } \\ \text { 'We have } 40 \text { volunteers who can run errands. They're all jumping through hoops here.' }\end{array}$

\section{External policies and regulations}

External guidelines 'I think the main cause is simply the nurses-to-patient ratio. [...] And everyone knows that, actually. Yes, on every level. Also, on the political level. And as long as there is no change there, basically nothing can change about these problems. [...] Not only on the labour market but also concretely at the patient's bedside, for the people. For the services that can be provided within the given framework conditions are declining. And at some point, something must happen in order to cause changes there.'

Economic pressure '[...] in my perception the health system, our health system is part of our whole ... our whole growth culture here. That there is incredible pressure, that the curves always have to go up, [...] there is of course also an external pressure.'

'So, there's no big profits going down here. And also economically, it is always a squaring of the circle, how do I manage it, right? To manage the whole thing financially somehow, with top medical quality. It's hard to achieve.'

\begin{tabular}{|c|c|}
\hline & $\begin{array}{l}\text { '[The required documentation] binds an incredible number of people who are also very well trained for the actual care of patients. } \\
{[\ldots . .] \text { if you add up how many people are involved in this every day [...] then we wouldn't be talking about a shortage of specialists }} \\
\text { if these people were available in large numbers for patient care [...]. Because it is already made extremely bureaucratic and } \\
\text { extremely time-consuming.' }\end{array}$ \\
\hline $\begin{array}{l}\text { Competence } \\
\text { assignments }\end{array}$ & $\begin{array}{l}\text { 'And I think we still have a lot of room to manoeuvre when it comes to the division of tasks among the health care professions. } \\
\text { But there are also barriers and boundaries, physicians do not want to do allocation, just delegation. Nursing staff no longer want } \\
\text { to be constantly patronized. [...] So, under delegation they are allowed to do everything, but being responsible and having an } \\
\text { independent attitude, that is not desired.' } \\
\text { 'It would make it much more patient-centered if therapists could just get started. [...] Meanwhile there are so many of them with } \\
\text { a master's degree or even a dissertation, therapists, I think you could manage that quite well without endangering patients. If you } \\
\text { wouldn't always involve the physician in the process.' }\end{array}$ \\
\hline $\begin{array}{l}\text { Decision makers at } \\
\text { system level }\end{array}$ & $\begin{array}{l}\text { '[...] there's the Medical Association, but there's no Nursing Association. So all these decisions are made by... by the physicians } \\
\text { and the medical lobby groups, right? But for nurses... it's very much in the hands of the physicians, in my opinion.' }\end{array}$ \\
\hline $\begin{array}{l}\text { Patient-directed } \\
\text { policies }\end{array}$ & $\begin{array}{l}\text { '[...] but politics has also done some good. The SAPV teams. This is an optimal and successful solution and we also notice (...?) } \\
\# 01: 13: 29 \# \text { as an improvement. Well, this regulation is really something where it made sense. [...] The SAPV team is available } \\
\text { around the clock, } 24 \text { hours a day, for the resident when he needs it.' }\end{array}$ \\
\hline Information & $\begin{array}{l}\text { disabled person's card, } \\
\text { I such things, right?' }\end{array}$ \\
\hline
\end{tabular}

HSCO, health and social care organisation; PCC, patient-centred care; SAPV, specialised outpatient palliative care.

providers reinforces PCC. On the other hand, insufficient or fragmented information technology (IT) structures lead to information gaps, hampering care provider cooperations. According to interviewees, there are no system-level incentives for the provision of an adequate digital infrastructure, which means that digitalisation depends on the willingness of individual providers to invest in it. The introduction of a central electronic healthcare platform where information about patients would be systematically collected was recommended as a strategy to facilitate cooperation among providers, bolstering transparency and providing information to patients.

\section{System processes}

\section{Continuity of care pathways and transition}

In the acute care context in particular, interviewees highlighted the importance of offering patients cross-sectoral continuity of care. They regarded immediate further treatment and cotreatment by other providers, including referrals and timely appointments, to be very important.
Decision makers of all care contexts agreed that separation of inpatient and outpatient sectors in terms of organisation and remuneration was a critical point in the provision of PCC. These processes are further complicated by other disruptive external factors, including shortages of specialists, psychotherapists and long-term care organisations.

The GP as gatekeeper concept was considered as a strategy with the potential to support PCC by managing and monitoring treatment paths.

\section{Communication and information transfer}

Many interviewees identified efficient communication and high-performance information systems as important prerequisites for PCC within organisations and between organisations. Mutual exchange or at least simple information sharing between HSCOs was described as essential to optimise treatment pathways and ensure continuity of care, especially in more complex cases. Next to improving patient care, information sharing was seen to harbour the 
potential to improve the efficiency of the whole system by reducing duplicate and unnecessary examinations.

As the system currently does not offer comprehensive cross-organisational information systems, there are many gaps and interface problems in the information transfer. Organisations addressed problems regarding the availability of prestationary medical information, information transfer after discharge and the lack of interaction with downstream providers to which their patients are sent for further treatment. In fact, most of the time, patients themselves are responsible for the transmission of relevant information. Only a few interviewees mentioned their efforts at communication with other providers and the sharing of patient-relevant information via telephone or fax.

\section{Cosmopolitanism and networks}

Beyond information transfer and communication, all outpatient decision makers addressed willingness to interact and collaborate in a structured way with other providers as a factor supporting PCC. This form of cosmopolitanism refers to the ability or willingness of an organisation to open up and network with persons or organisations outside its own boundaries. While interviewees particularly emphasised informal networks between HSCOs, they commented less on formal networks and contracts.

Decision makers mentioned examples of interdisciplinary and intersectoral networking promoting PCC such as structured collaboration with follow-up care providers in order to ensure continuity and quality of care or cooperation agreements with providers to guarantee basic medical care for long-term care residents. The special importance of networks was highlighted in the area of cancer treatment, with oncological centres ensuring all-round care, including diagnostics, radiation, chemotherapy and surgery, in both the outpatient and inpatient realms.

Specialised outpatient palliative care (SAPV) was mentioned as a positive example of how PCC can be promoted by networks. Through structured cooperation between SAPV teams and inpatient facilities such as longterm care or hospices, adequate and timely high-quality palliative care can be ensured.

\section{Collaboration between HSCOs and payers}

Similar to inadequate collaboration between providers, collaboration between providers and payers was also felt to have many problems with the practicability of processes and the duration of requests. Interviewees evaluated the bureaucratisation of processes as causing additional effort for providers and waste of resources. They stated that regulations and approvals from insurance companies are sometimes contrary to the needs of patients and medical indications. Interviewees complained that reimbursement requests for treatments are regularly denied even though they are medically justified. Routine delays in the authorisation of cost assumptions were perceived as extremely burdensome and potentially harmful to patients as were payment delays occasioned by social welfare authorities.

\section{Patient guidance and support}

Guiding patients through 'the healthcare jungle' was regarded as an important although currently underdeveloped part of PCC. In the absence of guidance, the fragmentation of the healthcare system and inadequate provider collaboration means that patients are set on treatment paths that are not targeted oriented, complicated or disconnected. In emergency departments, this disorientation is reflected by misdirected patient flows. Several interviewees felt that support options were especially required in the transition between the inpatient and outpatient sectors, a state of affairs that has been addressed by the recently introduced statutory discharge management in the German healthcare system.

The interviewees also associated PCC with educating patients about their rights and informing them about further support opportunities in addition to medical treatment at psychosocial care or advisory centres.

One interviewee suggested the introduction of patient guides, which might be provided by payers and might accompany and coordinate treatment across care providers.

\section{External resources}

Staffing

Interviewees identified a lack of human resources, inevitably accompanied by time scarcity, as a crucial factor influencing the adoption of PCC. Staff shortages were consistently linked to shortages of time allotted for patient care. Decision makers identified two external factors as having a bearing on the shortage of skilled workers in HSCOs: on the one hand, there is a shortage of skilled professionals in the labour market and, on the other hand, the financial resources provided for staffing in organisations are not sufficient to allow for a higher ratio of professionals to patients.

The interviewees agreed on the causes of staff shortages, identifying such factors as income, working hours and other working conditions. In the medical field, salary differences were presented as problematic because these lead to a concentration of personnel shortages in certain areas such as rehabilitation. The administrative burden and documentation effort, which occupies skilled workers with tasks that do not benefit patients, were also named as a cause of shortages.

\section{Qualification and education}

The shortage of skilled workers also causes problems in that organisations have to deal with less qualified staff and consequently lower rates of skilled employees within organisations which, according to interviewees, inevitably leads to lower quality of care. This problem was emphasised by decision makers in inpatient care organisations for acute care (hospitals) as well as by those in long-term care (long-term care organisations and hospices). 
Interviewees saw the integration of PCC contents into training as a precondition for PCC in actual patient care. Medical training, they argued, should be adapted to the changing needs of patients and society. As examples of this, interviewees brought up the care of geriatric patients with dementia or delirium and palliative care.

\section{Reimbursement of operating costs}

Interviewees in all care contexts called the reimbursement of healthcare services as the determinant of high interest. The control and incentive functions of reimbursement forms were seen as obstructive and, in certain respects, as being contrary to PCC and high-quality care.

Hospital decision makers perceived economic pressure as a result of flat rate payments via Diagnosis Related Groups (DRGs) because it may offer incentives to provide services solely for economic reasons. In particular, several interviewees described the documentation and administration required for reimbursement by social health insurances (SHIs) as a hindrance to focusing on patient-related work. Interviewees who worked in institutions under charitable ownership stated that there were intentions to use financial resources to finance patientoriented services even when they are not reimbursed.

Budgeting in the outpatient sector and bulk reimbursement for groups of services (in German: Leistungskomplexe) in long-term care limit providers in their scope of action because there is no flexibility to adapt care to the preferences or resources of the patient, especially treating 'special cases' in an adequate manner.

The separate financing schemes in inpatient and outpatient sectors render PCC more difficult at least in part because of efforts to ease cross-sectoral transitioning and cooperation, often causing financial losses to providers, and offering no incentives for providers to look beyond their own domains.

In all care contexts, interviewees described a lack of funding for communication with patients, relatives or other providers which, in their opinion, is an essential precondition for PCC.

\section{Financial incentives and investment costs}

Decision makers from acute inpatient care organisations pointed out that insufficient funds for equipment, investments or innovations prevented HSCOs from investing in health innovations that might ensure advanced patient care. Interviewees also reported a gap between the relatively abundant funds available for research and those available for implementation in practice.

Although interviewees regarded centres offering continuous care from a single source as very advanced and patient-oriented institutions, they criticised the number of surcharges. On the one hand, the surcharges were not sufficient to compensate for expenditures; on the other hand, they were not guaranteed in the long run. Notwithstanding current deficiencies, however, some decision makers cited different possible financing options supporting PCC, such as integrated provision contracts (in German: integrierte Versorgungsverträge).

\section{Community resources}

Only decision makers from long-term care organisations and hospices reported their utilisation of community resources in support of PCC. Community-aided services included collaboration with parishes to ensure assistance for patients after discharge and performance of nonmedical tasks by volunteers. In one example, only funding provided by a volunteer association made it possible to provide psychosocial care to patients. However, interviewees found the process of obtaining community resources difficult and time consuming.

\section{External policies and regulations}

\section{External guidelines}

Many decision makers perceived external regulations to be overly numerous and rigid. However, flexibility and a wide scope of action available to care providers were seen as preconditions for the provision of PCC. Inflexible external regulations cause problems that limit the number of therapy sessions or number of therapy days at the system level, although in contrast to regulatory authorities providers themselves are in a much better position to assess the number of sessions needed by individual patients with respect to their individual needs. The legally defined stability of contribution rates (in German: Beitragssatzstabilität) (Fundamental principle in statutory health insurance, which is intended to ensure that the expenditure of the statutory health insurance funds does not rise faster than their contribution-related income. (\$71, Sozialgesetzbuch (SGB V). Fünftes Buch Gesetzliche Krankenversicherung, 1989) $)^{35}$ was mentioned as external capping to meet the demands of the increasing number of patients and medical developments.

\section{Economic pressure}

Interviewees described the increasing focus of the healthcare system on profit and the resulting external economic pressure as hindering the implementation of PCC activities; in the outpatient sector by budgeting, and in the inpatient sector by DRGs or fixed cost degression (in German: Fixkostendegressionsabschlag) (Discount to be counted by hospitals that have agreed on additional healthcare services compared with the previous year in the annual budget negotiations with the social health insurances ( $\$ 4$, Krankenhausentgeltgesetz (KHEntgG), $\left.2003^{36}\right)$ ). Particularly in inpatient care, decision makers saw themselves as hard pressed, to balance high-quality care with the economic stability of organisations, a state of affairs potentially leading to disagreements over priorities between managers and healthcare professionals.

\section{Bureaucratisation and administration}

Interviewees from the inpatient sector stressed external administrative requirements and documentation efforts as an essential barrier to PCC. The availability of documentation was considered important, but decision 
makers described excessive bureaucratic documentation processes as a burden, tying up financial and human resources that are consequently unavailable for patient care. Above all, interviewees criticised the discrepancy between administrative burdens on the one hand and reimbursement of documentation time on the other.

\section{Competence assignments}

From some interviewees, impediments to PCC were identified in the externally imposed division of tasks between occupational groups and resulting constraints. In the hospital sector, this problem was especially evident in the division of tasks between physicians and nursing staff, and in the rehabilitation sector in the treatment options available to therapists, who can only deliver treatments ordered by physicians. Consequently, the expansion of competence areas and scope for action for individual occupational groups were described as supportive of PCC.

\section{Decision makers at system level}

Few interviewees from the nursing sector in hospitals and long-term care institutions criticised the lack of nursing representatives in important decision-making corporations such as the Federal Joint Committee. As a result, an important perspective on decisions affecting the healthcare system may be overlooked. This means that aspects relating to the adequate care of patients such as the ratio of professional to patient may not be considered to the same extent as strictly medical aspects.

\section{Patient-related policies}

Decision makers in all areas of care evaluated the influence of laws specifically designed to strengthen PCC in daily healthcare practices. Interviewees mentioned the federal drug plan, the legally binding provision of SAPV, the legally binding discharge management, and introduced psychotherapy reform including home treatment as examples that emphasise the policies' practical impact.

\section{Information}

Occasionally, interviewees described ways of disseminating information at the system level. According to them, PCC requires the public education of patients on their rights and available support options. The referenced means of public information to inform and empower patients included seminars and mass media campaigns.

\section{DISCUSSION}

To enable organisations to implement PCC activities, patient needs and resources need to be prioritised at the system level. ${ }^{24} 253738$ Against this background, this study aimed to identify facilitators and barriers to PCC implementation at the outer setting (system level) from the decision makers' perspective as well as by deriving measures and strategies to improve implementation. QCA of decision makers' interviews revealed an economically controlled alignment of the healthcare system through external regulations. Interviewees emphasised that lacking financial and human resources, sector separation, system processes preventing continuous care cycles and missing guidance and support for patients are obstacles for organisations introducing PCC activities.

Attributed to the extent of regulation of the German healthcare system, interviewees considered external policies and regulations as influencing the provider's practice to a large extent. The literature agrees that the implementation of PCC activities depends a lot on external policies. ${ }^{11}{ }^{20}$ Inpatient decision makers (hospitals and longterm care organisations) in particular perceived external guidelines as obstructive with regard to restrictions in fields of action and administration efforts. Participants discussed that the overall culture and orientation of the healthcare system are often not oriented towards patient needs, but increasingly oriented towards economic and financial objectives. Accordingly, healthcare associations call for a change from profit maximisation and revenuedriven care towards non-profit-oriented medicine with a greater focus on the well-being of patients. ${ }^{39}$

Overall, the system construction was identified as a hindering factor, since the strict separation of organisation and healthcare delivery in inpatient and outpatient sectors and deficits in healthcare capacities (eg, in psychotherapy or specialist care) lead to fragmented care processes and a lack of coordination, collaboration and continuity of care. ${ }^{182240}$ As a legally established approach to bridging the sector separation, structured discharge management has been established according to $\$ 39$ la of SGB V. Since then, hospitals in Germany have been legally obligated to prepare the discharge of patients from the hospital to a rehabilitation, outpatient or longterm care facility in order to avoid gaps in care due to a lack of coordinated follow-up treatment. ${ }^{35}$

Faced with limited financial resources and economic pressure, decision makers have perceived difficulties in finding the right balance of PCC, quality demands and economic performance. The separated remuneration structure between inpatient and outpatient providerscaused by sector separation and actual payment models focusing on the volume of healthcare services-apparently set incentives for organisations to follow only their own targets for a defined field of action instead of collaborating and providing continuous and coordinated care and transitions for patients during the whole care process. The findings of this study regarding financial determinants are consistent with previous work on PCC, which identified financing and payment models as crucial to adopting and maintaining new care structures. ${ }^{19241-43}$ One approach aiming to eliminate these financial obstacles and disincentives is the value-based healthcare approach, strongly influenced by Porter. ${ }^{44}$ Within that approach, value for patients is the goal that unites the interests of all healthcare system participants and should therefore be the focus of healthcare delivery and remuneration. Following the value-based approach, payment models that promote high value and patient-centredness need to be tied to achieving patient-relevant outcomes 
related to the full cycle of care. Porter and Lee ${ }^{23}$ proposed bundled payments to reimburse providers for all the care required to treat a patient's particular medical condition as an alternative to paying providers for each discrete service delivered in the care cycle. Another topic of this approach, which is consistent with the study's findings, is the meaning of interorganisational competition and peer pressure. Contrary to the literature, ${ }^{17} 194546$ interviewees described the motivation for the provision of PCC not as a competitive advantage but as the organisation's engagement and feeling of responsibility for care. Porter and Lee explained that competition in the healthcare system does not lead to value improvement and thus does not improve patient care if competitive incentives are related only to costs, bargaining or control over patients instead of to patient-relevant outcomes. ${ }^{23}$

Consistent with previous studies, the lack of IT infrastructure in the form of electronic information systems or health platforms is seen to impede the establishment of PCC structures. The interorganisational transfer of patient-specific clinical information could ensure consistent and continuous information transfer between providers to weaken the limitations and boundaries of sector separation. ${ }^{6723}$ Additionally, these structures may inform and empower patients, as well as improve information exchange between patients and providers. ${ }^{25}{ }^{40} \mathrm{In}$ Germany, the Law on Digital Health Care Provision (in German: Digitale-Versorgung-Gesetz) may bring PCC in the health service forward by the improved possibilities of information passing on, cooperation and transparency with nationwide electronic patient record and electronic prescriptions. ${ }^{47}$ Policymakers should more intensively discuss opportunities for improved IT structures in HSCOs systematically and comprehensively.

\section{Strengths and limitations}

Our study has several limitations. First, the interviewees only represent HSCOs in the German healthcare system, so the results are only conditionally transferable to healthcare systems of other countries. Nevertheless, there are multiple points of intersection in the identified determinants of PCC to different healthcare systems. The setting of the study, the city of Cologne, implies that determinants applied to more rural areas are neglected. However, some interviewees reported experiences in former places, in which the situation of healthcare deficits and staff shortages are even more acute. The literature also emphasises the importance of taking regional care situations and special features into account when planning and structuring future care concepts. Second, the sample of the interviewees might suffer from selection bias because the participants received no compensation. Consequently, it can be assumed that participants had higher motivation and interest in the research topic and might be more likely to put effort into PCC activities. The sample size of 20 interviews can also be seen as a limitation, as some care contexts are represented only by one HSCO. However, we consider the insider perspective of participants belonging to different types of HSCOs to be a strength. The findings of this study give an overview of the system-level factors considered decisive for PCC implementation from the decision makers' internal and practical viewpoint. Moreover, the diversity of interviewees from different healthcare sectors enables us to identify the interconnectedness of system-level determinants in different contexts.

\section{CONCLUSION}

System-level characteristics are associated with the way and extent to which HSCOs implement PCC activities (eg, external policies, financial resources, staff shortages, sector separation, digitalisation). A systematic, long-term planned strategy on the system level to improve PCC that extends across all organisations is lacking; rather, each organisation seeks its own possibilities to implement PCC activities under the external restrictions. For the success of PCC, it seems necessary to enforce paradigm shifts on the system level from disease-centredness to patient-centredness. Policy and reimbursement decisions should be aligned directly with patient needs and values to support collaboration and cooperation between providers. The action framework of providers should be expanded along care cycles to increase continuity of care. Improved and IT-supported guidance structures for patients to pass through pathways across providers and sector borders in a timely, efficient and targeted way may ensure coordination of care and prevent underuse, overuse or misuse of healthcare services.

Future research should apply in-depth analysis of individual facilitators and barriers to offer concrete policy implications to foster PCC implementation in organisations. As the findings of the study suggest that economic pressure and financial incentives are decisive for PCC implementation, future research should investigate whether specific reimbursement models and different forms of healthcare provision have an impact on PCC activities. Future research might focus on the impact of PCC on economic advantages and efficient healthcare provision. Various studies, ${ }^{48-50}$ such as that of Porter and Lee on the value-based healthcare approach, ${ }^{23}$ indicate that focusing on patient needs, outcomes and increased patient participation can lead to improved costeffectiveness. Furthermore, a detailed analysis of systematic differences between types or ownership of HSCOs is needed to validate the findings of this study.

\section{Author affiliations}

${ }^{1}$ University of Cologne, Cologne, Germany

${ }^{2}$ Institute for Health Economics and Clinical Epidemiology, University Hospital Cologne, Cologne, Germany

${ }^{3}$ Department of Business Administration and Health Care Management, University of Cologne, Cologne, Germany

${ }^{4}$ Department of Health Services Research, School of Medicine and Health Sciences, University of Oldenburg, Oldenburg, Germany, University of Oldenburg, Oldenburg, Germany

${ }^{5}$ Institute of Medical Sociology, Health Services Research, and Rehabilitation Science (IMVR), Faculties of Human Sciences and Medicine, University of Cologne, Cologne, Germany 
Twitter Holger Pfaff @PfaffHolger

Acknowledgements We thank all the participants of this study for sharing their experiences.

Collaborators The CoRe-Net Co-applicants are Christian Albus, Lena Ansmann, Frank Jessen, Ute Karbach, Ludwig Kuntz, Holger Pfaff, Christian Rietz, Ingrid Schubert, Frank Schulz-Nieswandt, Stephanie Stock, Julia Strupp and Raymond Voltz.

Contributors LA, SS, LK and HP conceived the study. KIH, VV and HH specified the methods. $\mathrm{KIH}, \mathrm{V}$ and $\mathrm{HH}$ conducted the interviews. $\mathrm{KIH}, \mathrm{V}, \mathrm{HH}$ and $\mathrm{CL}$ analysed the interviews. CL drafted and revised the manuscript in cooperation with $\mathrm{KIH}$ and V. All authors critically read, revised and approved the final manuscript. CL is the guarantor of the study.

Funding This work was supported by the German Federal Ministry of Education and Research (grant number 01GY1606).

Competing interests None declared.

Patient consent for publication Not required.

Ethics approval The Ethics Committee of the Medical Faculty of the University of Cologne approved the study (reference number: 17-210). All participants provided written informed consent. All participants who travelled to the University Hospital Cologne were covered by travel insurance.

Provenance and peer review Not commissioned; externally peer reviewed.

Data availability statement Data are available upon reasonable request. No additional data are available.

Supplemental material This content has been supplied by the author(s). It has not been vetted by BMJ Publishing Group Limited (BMJ) and may not have been peer-reviewed. Any opinions or recommendations discussed are solely those of the author(s) and are not endorsed by BMJ. BMJ disclaims all liability and responsibility arising from any reliance placed on the content. Where the content includes any translated material, BMJ does not warrant the accuracy and reliability of the translations (including but not limited to local regulations, clinical guidelines, terminology, drug names and drug dosages), and is not responsible for any error and/or omissions arising from translation and adaptation or otherwise.

Open access This is an open access article distributed in accordance with the Creative Commons Attribution Non Commercial (CC BY-NC 4.0) license, which permits others to distribute, remix, adapt, build upon this work non-commercially, and license their derivative works on different terms, provided the original work is properly cited, appropriate credit is given, any changes made indicated, and the use is non-commercial. See: http://creativecommons.org/licenses/by-nc/4.0/.

ORCID iDs

Vera Vennedey http://orcid.org/0000-0003-4977-750X

Kira Isabel Hower http://orcid.org/0000-0002-7123-3296

\section{REFERENCES}

1 World Health Organization. People-centred health care: a policy framework. World Health Organization, 2007.

2 Kitson A, Marshall A, Bassett K, et al. What are the core elements of patient-centred care? A narrative review and synthesis of the literature from health policy, medicine and nursing. J Adv Nurs 2013;69:4-15.

3 Paparella G. Person-centred care in Europe: a cross-country comparison of health sytem performance, strategies and structures. Oxford, England: Picker Institute Europe, 2016.

4 Mead N, Bower P. Patient-centred consultations and outcomes in primary care: a review of the literature. Patient Educ Couns 2002;48:51-61.

5 Epstein RM, Street RL. The values and value of patient-centered care. Ann Fam Med 2011;9:100-3.

6 Institute of Medicine (US) Committee on Quality of Health Care in America. Crossing the quality chasm: a new health system for the 21st century. Washington(DC: Institute of Medicine (US) Committee on Quality of Health Care in America, 2001.

7 McMillan SS, Kendall E, Sav A, et al. Patient-centered approaches to health care: a systematic review of randomized controlled trials. Med Care Res Rev 2013;70:567-96.

8 Epstein RM, Fiscella K, Lesser CS, et al. Why the nation needs a policy push on patient-centered health care. Health Aff 2010;29:1489-95.
9 Little P, Everitt H, Williamson I, et al. Preferences of patients for patient centred approach to consultation in primary care: observational study. BMJ 2001;322:468.

10 Rathert C, Wyrwich MD, Boren SA. Patient-centered care and outcomes: a systematic review of the literature. Med Care Res Rev 2013;70:351-79.

11 Scholl I, LaRussa A, Hahlweg P, et al. Organizational- and systemlevel characteristics that influence implementation of shared decision-making and strategies to address them - a scoping review. Implement Sci 2018;13:40.

12 Ansmann L, Hillen HA, Kuntz L, et al. Characteristics of value-based health and social care from organisations' perspectives (OrgValue): a mixed-methods study protocol. BMJ Open 2018;8:e022635.

13 Hower KI, Vennedey V, Hillen HA. Implementation of patient centred care: which organisational determinants matter from decision maker's perspective? Results from a qualitative interview study across various health and social care organisations. BMJ Open 2019;9:e027591.

14 Moore L, Britten N, Lydahl D, et al. Barriers and facilitators to the implementation of person-centred care in different healthcare contexts. Scand J Caring Sci 2017;31:662-73.

15 May C, Finch T, Mair F, et al. Understanding the implementation of complex interventions in health care: the normalization process model. BMC Health Serv Res 2007;7:148.

16 Fix GM, VanDeusen Lukas C, Bolton RE, et al. Patient-centred care is a way of doing things: how healthcare employees conceptualize patient-centred care. Health Expect 2018;21:300-7.

17 Damschroder LJ, Aron DC, Keith RE, et al. Fostering implementation of health services research findings into practice: a consolidated framework for advancing implementation science. Implement Sci 2009;4:50.

18 Bergeson SC, Dean JD. A systems approach to patient-centered care. JAMA 2006:296:2848-51.

19 Greenhalgh T, Robert G, Macfarlane F, et al. Diffusion of innovations in service organizations: systematic review and recommendations. Milbank Q 2004;82:581-629.

20 Wagner EH, Austin BT, Davis C, et al. Improving chronic illness care: translating evidence into action. Health Aff 2001;20:64-78.

21 Ashton T. Implementing integrated models of care: the importance of the macro-level context. Int J Integr Care 2015;15:e019.

22 Aldridge MD, Hasselaar J, Garralda E, et al. Education, implementation, and policy barriers to greater integration of palliative care: a literature review. Palliat Med 2016;30:224-39.

23 Porter ME, Lee TH. The strategy that will fix health care. Harvard Business Rev 2013:1-19.

24 Davy C, Bleasel J, Liu H, et al. Factors influencing the implementation of chronic care models: a systematic literature review. BMC Fam Pract 2015;16:102.

25 Santana MJ, Manalili K, Jolley RJ, et al. How to practice person-centred care: a conceptual framework. Health Expect 2018;21:429-40.

26 The German health care system. Institute for quality and efficiency in health care (IQWiG). Health care in Germany: the German health care system, 2015.

27 Stock S. Integrated ambulatory specialist care-Germany's new health care sector. N Engl J Med 2015;372:1781-5.

28 Institute for Quality and Efficiency in Health Care. What are disease management programs (DMPS)? 2019. https://www.informedhealth. $\mathrm{org} /$ what-are-disease-management-programs-dmps.2265.en.html

29 Stock S, Pitcavage JM, Simic D, et al. Chronic care model strategies in the United States and Germany deliver patient-centered, highquality diabetes care. Health Aff 2014;33:1540-8.

30 Nolte E, Knai C, Hofmarcher M, et al. Overcoming fragmentation in health care: chronic care in Austria, Germany and the Netherlands. Health Econ Policy Law 2012;7:125-46.

31 Härter M, Dirmaier J, Scholl I, et al. The long way of implementing patient-centered care and shared decision making in Germany. $Z$ Evid Fortbild Qual Gesundhwes 2017:123-124:46-51.

32 Karbach U, Ansmann L, Scholten N, et al. Bericht AUS einem laufenden forschungsprojekt: coRe-Net, das Kölner kompetenznetzwerk AUS versorgungspraxis und versorgungsforschung, und Der value-based healthcareansatz. Zeitschrift für Evidenz, Fortbildung und Qualität im Gesundheitswesen 2018;130:21-6.

33 Miles MB, Huberman AM, Saldaña J. Qualitative data analysis: a methods sourcebook. Thousand Oaks, California: SAGE Publications, Inc, 2014.

34 Saldaña J. The coding manual for qualitative researchers. Los Angeles: SAGE, 2009.

35 Sozialgesetzbuch (SGB V). Fünftes Buch Gesetzliche Krankenversicherung, 1989. 
36 Krankenhausentgeltgesetz - KHEntgG. Gesetz über die Entgelte für voll- und teilstationäre Krankenhausleistungen; 2003.

37 Grol R, Grimshaw J. From best evidence to best practice: effective implementation of change in patients' care. Lancet 2003;362:1225-30.

38 Keith RE, Crosson JC, O'Malley AS, et al. Using the consolidated framework for implementation research (CFIR) to produce actionable findings: a rapid-cycle evaluation approach to improving implementation. Implement Sci 2017;12:15.

39 Association of the Scientific Medical Societies in Germany. Medizin und Ökonomie - Maßnahmen für eine wissenschaftlich begründete, patienten-zentrierte und ressourcenbewusste Versorgung, 2018. Available: https://www.awmf.org/fileadmin/user upload/Stellungnahmen/Medizinische_Versorgung/20181205_ Medizin_und_\%C3\%96konomie_AWMF_Strategiepapier_V1. OmitLit.pdf

40 Pelzang R. Time to learn: understanding patient-centred care. $\mathrm{Br} \mathrm{J}$ Nurs 2010;19:912-7.

41 Aarons GA, Hurlburt M, Horwitz SM. Advancing a conceptual model of evidence-based practice implementation in public service sectors. Adm Policy Ment Health 2011;38:4-23.

42 Moore SL, Fischer I, Havranek EP. Translating health services research into practice in the safety net. Health Serv Res 2016;51:16-31.
43 Lüdecke D. Patient centredness in integrated care: results of a qualitative study based on a systems theoretical framework. Int $J$ Integr Care 2014;14:1-9.

44 Porter ME. What is value in health care? N Engl J Med 2010;363:2477-81.

45 Yang C-W, Fang S-C, Huang W-M. Isomorphic pressures, institutional strategies, and knowledge creation in the health care sector. Health Care Manage Rev 2007;32:263-70.

46 Feldstein AC, Glasgow RE, practical A. A practical, robust implementation and sustainability model (PriSM) for integrating research findings into practice. Jt Comm J Qual Patient Saf 2008;34:228-43.

47 Bundesministerium für Gesundheit. Gesetz für eine bessere Versorgung durch Digitalisierung und Innovation (Digitale-VersorungGesetz - DVG), 2019. Available: https://www.bundesgesundheitsmin isterium.de/digitale-versorgung-gesetz.html

48 Stone S. A retrospective evaluation of the impact of the Planetree patient-centered model of care on inpatient quality outcomes. HERD 2008;1:55-69.

49 Olsson L-E, Hansson E, Ekman I, et al. A cost-effectiveness study of a patient-centred integrated care pathway. J Adv Nurs 2009;65:1626-35.

50 Reid RJ, Fishman PA, Yu O, et al. Patient-centered medical home demonstration: a prospective, quasi-experimental, before and after evaluation. Am J Manag Care 2009;15:e71-87. 